\title{
Mediation effects of innovative procurement practices between the determinants of non-compliance with public procurement guidelines and construction project cost performance in the Nigerian construction industry
}

\author{
N. Z. Abdullahi ${ }^{1,2}$, A. A. Hussin ${ }^{1} \&$ A. Osmadi ${ }^{1}$ \\ ${ }^{1}$ School of Housing Building and Planning, \\ Universiti Sains Malaysia, Malaysia \\ ${ }^{2}$ Department of Quantity Surveying, \\ School of Environmental Technology, \\ Abubakar Tafawa Balewa University, Nigeria
}

\begin{abstract}
As part of the effort towards achieving sustainable planning and development of public infrastructure and building projects in Nigeria, Public Procurement Guidelines (PPGs) were highlighted within the procurement policy enacted in 2007 known as PPA2007. Compliance among construction procurement professionals and project parties has been facing serious challenges. Unfamiliarity, misconception and ignorance with the PPGs are identified as the major determinants of non-compliance affecting cost performance of construction projects. The study introduced and tested mediation effects of innovative procurement practices between the identified determinants and cost performance of construction projects in Nigeria. 540 survey questionnaires were used in collecting data, PROCESS macro software was used in analysing 379 useable retrieved questionnaires. Findings indicated that innovative procurement practices have mediated the effects of the determinant of non-compliance with PPGs on construction project cost performances. The study recommends enlightening and educating procurement stakeholders and major project parties on the cost benefits
\end{abstract}


of innovative procurement practices. These may perhaps enhance compliance with PPGs, improve cost performance and sustainable development of projects.

Keywords: mediation, innovative procurement practices, determinants, compliance, public procurement guidelines, project performance, Nigeria.

\section{Introduction}

Construction procurement as a sub-element of public procurement is one of the key activities of the construction industry globally, which contributes immensely to the development of every nation (Inuwa and Diang'a [1] and Abdullahi et al. [2]). The construction industry provides infrastructure facilities in addition to job creation, wealth accumulation and general contribution to the Gross Domestic Product (GDP) of countries (Abdullahi et al. [2], Kamar and Hamid [3] and Inuwa et al. [4].

The Nigerian construction industry contributes 1.4\% to the GDP (Odediran et al. [5]), creates $25 \%$ of employment slots of the country's workforce (Ibrahim and Musa-Haddary [6]), and about $70 \%$ of the country's fixed capital formation is attached to the construction industry (Inuwa et al. [4]). PPGs is a sectional part of PPA2007, issued with the aim of transforming the public procurement sector especially the rampant irregularities in construction project delivery (Shehu [7] and Williams-Elegbe [8]). Unfortunately, construction industry professionals are recognised with selective implementation and in some cases non-compliance to the PPGs (Abdullahi et al. [2], Fayomi [9], Jibrin et al. [10]). Ademola and Ajibola [11] claims that this is affecting the performance of construction projects especially in terms of cost (Abdullahi et al. [2] and Ayangade et al. [12]). This study is aimed at achieving the following objectives: (1) To assess the causal relationship between the identified determinant of non-compliance to PPGs and construction project cost performance; (2) To examine the mediating effects of innovative procurement practices between the determinant of compliance to PPGs and cost performance of construction projects; (3) To develop compliance with PPGs mediating model based on innovative procurement practices that will improve cost performance of construction projects.

\section{Public procurement guidelines (PPGs) and compliance issues}

Sustainable planning and development of infrastructure projects was part of the motive of procurement sector reform initiatives in Nigeria. PPGs were issued as a section of PPA2007 to be used as a public procurement manual, and it is divided into the four main parts (Shehu [7]): (1) Monetary Guidelines; (2) Process Guidelines; (3) Responsibility Guidelines; (4) Procurement Method Guidelines.

Although PPGs were inevitably meant to regulate public procurement practices, and were prompted for best practice to align with international standard (Ademola and Ajibola [11]), but ample challenges surround its implementation especially in developing countries (Abdullahi et al. [2], Jibrin et al. [10], Hui et al. [13]). 


\subsection{Unfamiliarity with public procurement guidelines}

Unfamiliarity is the main study independent construct. Familiarity with the guidelines is a strong compliance determinant or variable, for the construction procurement stakeholders to appropriately implement the PPGs they ought to be familiar with its contents (Abdullahi et al. [2]). Unfortunately, stakeholders including professionals are observed with unfamiliarity with the PPGs (Shehu [7], Fayomi [9], Migosi et al. [14]), leading to pitiable delivery of infrastructure and poor cost performance of projects in the long run (Ojo and Gbadebo [15]).

\subsection{Cost performance of construction projects}

Cost is as an important measurement construct that runs throughout the project management life cycle. Accordingly, cost is considered as a fundamental driving force of project success and subsequent performance (Azhar et al. [16]). Construction project consume huge financial resources, project delivered within budgeted cost is said to have perform well cost wise (Bima et al. [17]). Appropriate choice of procurement systems and rightful application of PPGs helps in keeping project within budgeted cost and time schedules (Memon et al. [18], Shwarka and Anigbogu [19]). Based on the effects of PPGs compliance determinants on construction cost, construction project cost performance is the independent construct of this study.

\subsection{Innovative procurement practices (mediating variable)}

Innovation literally means compliance to significantly new or improved techniques, approaches, strategies, processes, and business practices aimed at addressing certain challenges. Prior studies found vital reasons for inducing innovative practice in public procurement as a tool for sustainable developments, for example the studies of Edquist [20], Hommen and Rolfstam [21] and Rolfstam [22] reported that innovation is promoted in public procurement by institutionalising public procurement systems which brings practical policymaking a reality because it encourages compliance with procedural manual and guidelines such as PPGs. Accordingly, this study proposed innovate procurement practice as a mediator to improve the effects of the independent and the dependent construct of the study.

\subsection{Conceptual mediation model of the study}

To develop the mediation model by testing the hypothesis as stated in the study objectives, a conceptual model is proposed (as shown in figure 1). The proposed framework shows the relationship between the study independent, dependent and mediating variables. Unfamiliarity is the independent variable; innovative procurement practices is the mediating variable and cost performance is the dependent or outcome variable of the study. Figure 1(a) shows the total effect portion of the model path-c, while figure 1(b) presents the direct effect and the indirect mediation effects of the proposed model path-a, path-b and path-c'. 


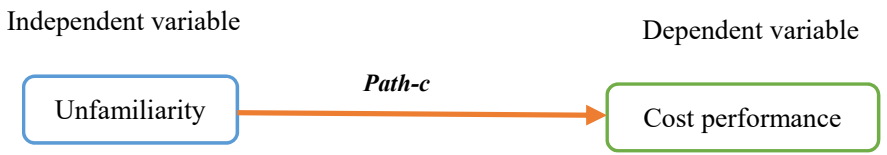

(a)

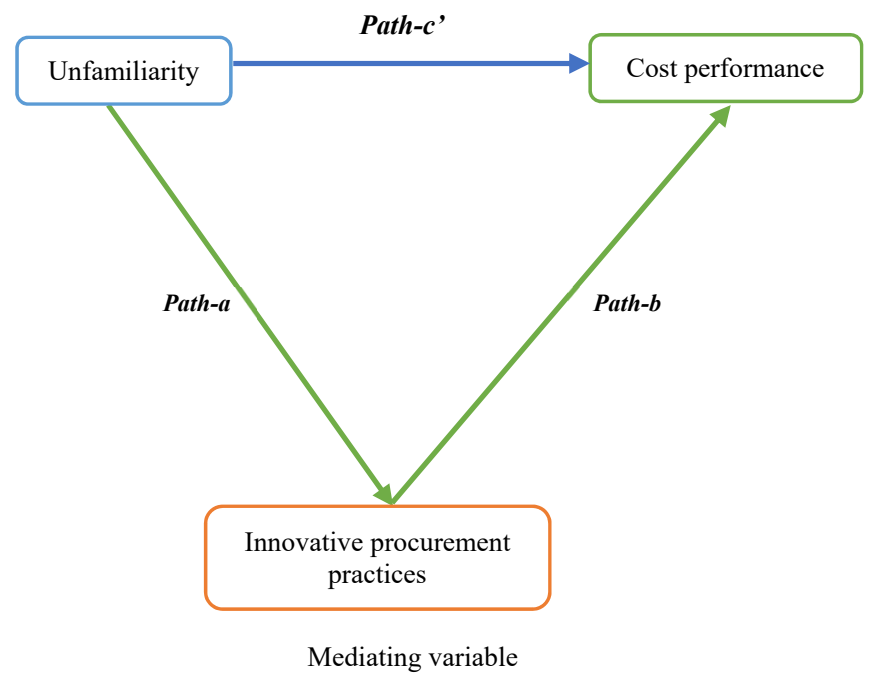

(b)

Figure 1: Conceptual mediation model of the study: (a) Total effect model and (b) Direct and indirect effects model.

\section{Research methodology}

Questionnaire survey been the appropriate instrument was used in collecting primary data for this study (Sekaran [23]). It was designed with the five-point Likert scale; 1 for strongly disagree and 5 for strongly agree. Giudici [24] posited that the Likert scale is the most widely used scale in measuring research variables that ensures consistency. Content of the instrument was validated, construct reliability was achieved using factor analysis as presented in table 1 , the result shows good internal consistency.

Table 1: $\quad$ Factor analysis from pilot testing.

\begin{tabular}{|c|c|c|c|}
\hline Construct & Dimension & Number of items & Cronbach's Alpha \\
\hline Familiarity & Misconception & 10 & 0.746 \\
\hline Familiarity & Ignorance & 11 & 0.747 \\
\hline $\begin{array}{c}\text { Mediating } \\
\text { variable }\end{array}$ & Innovative procurement practices & 10 & 0.789 \\
\hline Outcome & Cost performance & 11 & 0.784 \\
\hline
\end{tabular}




\subsection{Data collection and analysis}

A total of 540 questionnaires were randomly distributed to construction procurement stakeholders as major projects parties in procurement entities of randomly choose federal universities in northern Nigeria, selected using stratified random sampling method. 410 questionnaires were returned, while 379 were used for the analysis yielding $76 \%$ and $70 \%$ return and response rate respectively. PROCESS macro software written by Hayes [25] was used for the mediation analysis, it is one of the newest mediation tool used as a regression-based package capable of analysing more than 70 different mediation and moderation models (Preacher and Hayes [26]). Two different mediation methods were used, that is Bootstrap confidence interval and Sobel Test methods.

\subsection{Result presentation}

\subsubsection{Effects of unfamiliarity on innovative procurement practices (path-a)}

Result of the effects of unfamiliarity (IV) on innovative procurement practices (MV) is presented in table 2. The coefficient obtained on path- $a$, is 0.4113 and the test of statistical coefficient $t=31.8749$, while $\mathrm{p}=0.0000(\mathrm{p}<0.05)$. The lower limit confidence interval (LLCI) is 0.3859 and the upper limit confidence interval (ULCI) is 0.4367 , the output based on the p-value $(\mathrm{p}<0.05)$, and both LLCI and ULCI values $\neq 0$ indicates significant effects between the unfamiliarity (IV) and innovative procurement practices (MV) thus satisfying first condition of mediation (Hayes [27] and Baron and Kenny [28]).

Table 2: Effects of the relationship along a-path.

\begin{tabular}{|l|l|l|l|l|l|l|}
\hline \multicolumn{7}{|c|}{ Outcome: innovative procurement practices } \\
\hline R & R-sq & MSE & F & df1 & df2 & p \\
\hline 0.8556 & 0.7230 & 0.0414 & 1016.0087 & 1.0000 & 372.0000 & 0.0000 \\
\hline \multicolumn{7}{|c|}{ Main model } \\
\hline & Coeff & se & t & p & LLCI & ULCI \\
\hline Constant & 0.4329 & 0.0740 & 5.6192 & 0.0000 & 0.2814 & 0.5843 \\
\hline Unfamiliarity & 0.4113 & 0.0129 & 31.8749 & 0.0000 & 0.3859 & 0.4367 \\
\hline
\end{tabular}

\subsubsection{Direct and indirect effects of the study model (path-a and path-b)}

The mediation coefficient along path- $b$ is $0.0262, \mathrm{p}=0.0001(\mathrm{p}<0.05)$, test of statistical significance $\mathrm{t}=0.5732$ while lower and upper confidence interval (LLCI and ULCI) obtained along path $-b$ are 0.0635 and 0.1159 respectively. The result indicates significant effects and has fulfilled second condition of mediation (Baron and Kenny [28]). In addition, the second result as presented in table 3 provides path-c' coefficient as $0.3384, \mathrm{p}=0.3718(\mathrm{p}>0.05)$, LLCI and ULCI obtained are 0.2952 and 0.3815 respectively. P-value $<0.05$ which insignificant effects along path-c', Consequently, the result obtained has fulfilled the fourth condition of mediation by obtaining insignificant effects between IV and DV after adding MV in the model as presented in table 3 (Hayes [27] and Baron and Kenny [28]). 
Table 3: Direct and indirect effects (path-b and path-c').

\begin{tabular}{|c|c|c|c|c|c|c|}
\hline \multicolumn{7}{|c|}{ Main model, outcome: cost performance } \\
\hline & Coeff & $\mathrm{Se}$ & $\mathrm{t}$ & $\mathrm{P}$ & LLCI & LLCI \\
\hline Constant & 0.8157 & 0.0706 & 11.5463 & 0.0000 & 0.6768 & 0.9546 \\
\hline $\begin{array}{c}\text { Innovative } \\
\text { procurement } \\
\text { practices }\end{array}$ & 0.0262 & 0.0451 & 0.5732 & 0.0001 & 0.0636 & 0.1159 \\
\hline Unfamiliarity & 0.3384 & 0.0219 & 15.4175 & 0.3718 & 0.2952 & 0.3815 \\
\hline
\end{tabular}

\subsubsection{Total effects between unfamiliarity and cost performance (path-c)}

The coefficient for the total effect in the model obtained is $0.3391 \mathrm{p}$-value $=0.0000$ $(\mathrm{p}<0.05)$ and a test of statistical significance t (30.7561) while LLCI and ULCI are 0.3268 and 0.3714 respectively. The result indicates significant effects; thus, the model satisfies the third condition of the mediation model as presented in table 4 (Baron and Kenny [28]).

Table 4: Total effects between IV and DV (path-c).

\begin{tabular}{|c|c|c|c|c|c|c|}
\hline \multicolumn{7}{|c|}{ Outcome: cost performance } \\
\hline $\mathrm{R}$ & R-sq & MSE & $\mathrm{F}$ & df1 & df2 & $\mathrm{p}$ \\
\hline 0.8472 & 0.7177 & 0.0320 & 945.9355 & 1.0000 & 372.0000 & 0.0000 \\
\hline \multicolumn{7}{|c|}{ Main model } \\
\hline & coeff & $\mathrm{Se}$ & $\mathrm{T}$ & $\mathrm{p}$ & LLCI & ULCI \\
\hline Constant & 0.8270 & 0.0678 & 12.2044 & 0.0000 & 0.6938 & 0.9603 \\
\hline Unfamiliarity & 0.3491 & 0.0114 & 30.7561 & 0.0000 & 0.3268 & 0.3714 \\
\hline
\end{tabular}

\subsection{Discussion of findings}

In recent times, mediation analysis and confirmation of mediation effects' occurrence in a model is judged based on indirect effects i.e. effects along path-a, and path- $b$ (Hayes [29]). Statistically, indirect effects are the difference between total effects (path-c) and direct effects in the model, and the result should be equal to the product of path-a, and path-b (Hayes and Preacher [30]).

i.e. mediation or indirect effects $c-c^{\prime}=(0.3491-0.3384)=0.0108$.

Then again mediating or indirect effects $=\mathrm{a} * \mathrm{~b}=(0.4113 * 0.0262)=0.0108$

Equally the mediating or indirect effect automatically generated by the PROCESS macro software is 0.0108 (as shown in table 5).

The occurrence of mediation effects in the study model is further confirmed with Sobel-Test method, this was intended to further confirm and validate the first result obtained via Bootstrap Confidence Interval method as statistically recommended (MacKinnon et al. [31] and Hayes [32]). The indirect effect from the Sobel Test result is 0.0108 which is the same value of the indirect effects 
obtained via Bootstrap confidence interval method i.e. (a-path *b-path) and (c$\left.c^{\prime}\right)$. This shows consistency between two results obtained via different approaches, and the value is different from zero which further confirm mediation occurrence in the study model with $\mathrm{Z}=0.5728$ and $\mathrm{p}=0.0012(\mathrm{p}<0.05)$ (as shown in table 6).

Table 5: Total, direct and indirect effects of the study model.

\begin{tabular}{|c|c|c|c|c|c|}
\hline \multicolumn{6}{|c|}{ Total effect of unfamiliarity (IV) on cost performance (DV) } \\
\hline Effect & SE & $\mathrm{t}$ & $\mathrm{p}$ & LLCI & ULCI \\
\hline 0.3491 & 0.0114 & 30.7561 & 0.0000 & 0.3268 & 0.3714 \\
\hline \multicolumn{7}{|c|}{ Direct effect of unfamiliarity (IV) on cost performance (DV) } \\
\hline Effect & SE & $\mathrm{t}$ & $\mathrm{p}$ & LLCI & ULCI \\
\hline 0.3384 & 0.0219 & 15.4175 & 0.0000 & 0.2952 & 0.3815 \\
\hline \multicolumn{6}{|c|}{ Indirect effect of unfamiliarity (IV) on cost performance (DV) } \\
\hline $\begin{array}{c}\text { Innovative } \\
\text { procurement } \\
\text { practices }\end{array}$ & Effect & Boot SE & Boot LLCI & Boot ULCI & \\
\hline
\end{tabular}

Table 6: Sobel Test confirmatory result for the study model.

\begin{tabular}{|c|c|c|c|c|}
\hline \multicolumn{5}{|c|}{ Preacher and Kelley [34] Kappa-squared } \\
\hline & Effect & Boot SE & Boot LLCI & Boot ULCI \\
\hline $\begin{array}{c}\text { Innovative procurement } \\
\text { practices }\end{array}$ & 0.5371 & 0.0378 & 0.4570 & 0.6066 \\
\hline \multicolumn{5}{|c|}{ Normal theory test for indirect effects } \\
\hline Effect & $\mathrm{Se}$ & $\mathrm{Z}$ & $\mathrm{P}$ \\
\hline 0.0108 & 0.0188 & 0.5728 & 0.0012 \\
\hline
\end{tabular}

Decisively, innovative procurement practice has partially mediated the effects of unfamiliarity with the application of public procurement guidelines (PPGs) among major construction procurement stakeholders which will subsequently improve cost performance of construction projects, and enhance sustainable planning and development of infrastructure and building projects.

Prior studies found vital reasons for inducing innovative practice in public procurement as a reliable tool for sustainable planning and developments of projects, these includes the studies of Edquist [20], Hommen and Rolfstam [21] and Edquist [20]. In contrast, the findings of Uyarra and Flanagan [33] disputed on the potentiality of innovative practices for sustainable development of public infrastructure, claiming that objectives of innovation might not appropriately tally with public interest. Accordingly, the findings of this study contradict that of Uyarra and Flanagan [33] and argues that innovativeness is promoted in public procurement by institutionalising public procurement systems which brings practical policy-making a reality and positively affects cost performance of construction projects based on the mediation result as above. The developed 
mediation model of the study is presented in figure 1 showing all the coefficients along the paths that makes up the model.

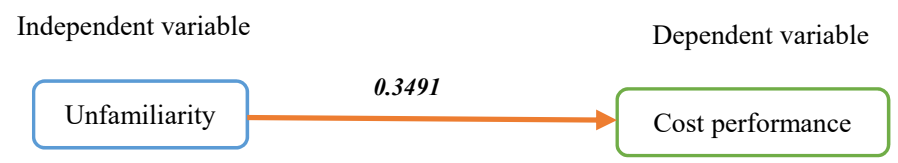

(a)

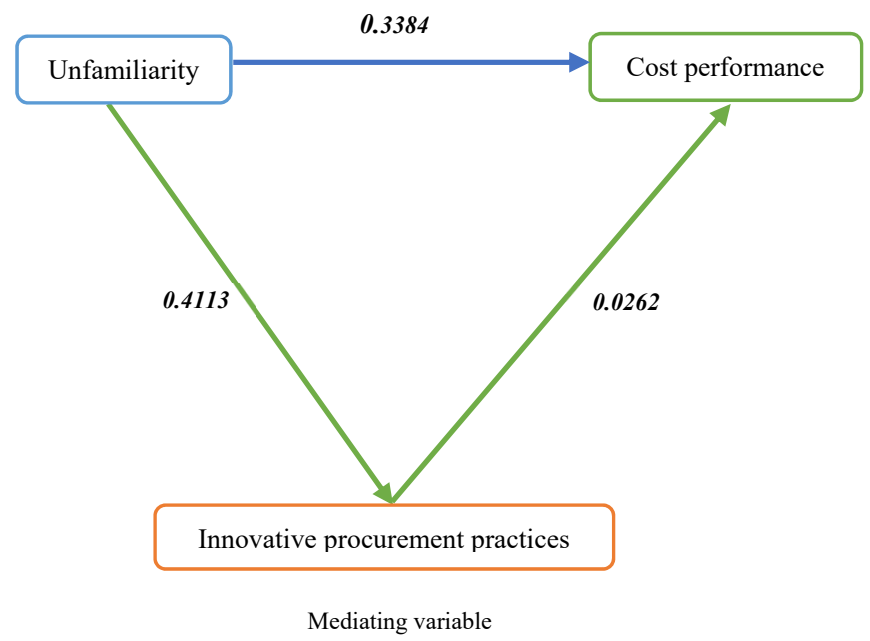

(b)

Figure 2: Final mediation model of the study: (a) Total effect model and (b) Direct and indirect effects model.

\section{Conclusion and recommendation}

This study aimed to ascertain the mediation effects of innovative procurement practices on non-compliance with public procurement guidelines (PPGs) for improving cost performance of construction projects. Unfamiliarity with PPGs inform of misconception and total ignorance with the guidelines were identified as the barriers to compliance and referred to as the independent construct of this study affecting cost performance as the dependent construct of the study. The mediation effects obtained indicates that, innovative procurement practice has mediated the effects of unfamiliarity with the PPGs on cost performance of construction projects. Therefore, by encouraging innovative procurement practices among major construction procurement stakeholders and project parties they will tend to be more familiar with the appropriate procurement procedural 
requirement (PPGs) and how to comply with the whole procurement procedural guidelines. This will possible yield reasonable level of compliance and will conceivably improve performance of construction projects cost-wise. In the long run, the resultant effects will lead to sustainable planning and development of public projects in most developing economies especially Nigeria. The research recommends that future researchers should focus on testing the developed model for moderating effects.

\section{Acknowledgement}

The authors would like to acknowledge the support of Universiti Sains Malaysia for this study, through the USM Postgraduate fellowship scheme.

\section{References}

[1] Inuwa, I.I. and S. Diang'a, Effective Procurement Practices in a Developing Economy for Sustainable Construction. ATBU Journal of Environmental Technology, 8(2), pp. 64-78, 2015.

[2] Abdullahi, N.Z., A.A. Hussin and A. Osmadi, Determinants of Compliance with Public Procurement Guidelines in The Nigerian Construction Industry Jurnal Teknologi, 75(9), 2015.

[3] Kamar, K. and Z. Hamid, Sustainable Construction of Green Building: The case of Malaysia. Sustainability Today, 167, p. 15, 2012.

[4] Inuwa, I.I., W. Githae and S. Diang'a, Construction Procurement Systems: Influencing Factors for Nigerian Indigenous Contractors' Project Planning International Journal of Engineering Research \& Technology 3(4), pp. 1043-1050, 2014.

[5] Odediran, S.J. et al., Business Structure of Indigenous Firm in the Nigerian Construction Industry. International Journal of Business Research and Management, vol. 3 (5), pp. 255-264, 2012.

[6] Ibrahim, A. and Y. Musa-Haddary. Concept of value for money in public infrastructure development. in International Workshop on PPP Approach for Infrastructure Development in Nigeria. 2010.

[7] Shehu, A.S. An Overview of Public Procurement Guidelines in Nigeria. in Institute of Quantity Surveyors National Seminar 'Procurement of Construction Works and Services - Adapting to Contemporary Challenges'. 2014. Gombe International Hotel, Nigeria.

[8] Williams-Elegbe, S., The Reform and Regulation of Public Procurement in Nigeria. Pub. Cont. LJ, 41, p. 339, 2011.

[9] Fayomi, I.O., Public procurement and due process policy in Nigeria: Thrust, prospects and challenges. Peak Journal of Social Sciences and Humanities, 1(4), pp. 39-45, 2013.

[10] Jibrin, M.S., S.B. Ejura and N.I. Augustine, The Public Procurement Reforms in Nigeria: Implementation and Compliance Challenges. Journal of Asian Business Strategy, 4(11), pp. 149-162, 2014. 
[11] Ademola, E.O. and M.G. Ajibola, An Assessment of Non-Compliance with Procurement Proceedings in Procurement of Works in Nigeria. International Journal of Economic and Business Management, 2(3), pp. 2534, 2014.

[12] Ayangade, J., A. Wahab and O. Alake, An Investigation of the Performance of Due Process Mechanism in the Execution of Construction Projects in Nigeria. Civil Engineering Dimension, 11(1), pp. 1-7, 2009.

[13] Hui, S.W. et al., Procurement issues in Malaysia. International journal of public sector Management, 24(6), pp. 567-593, 2011.

[14] Migosi, J.A. et al., Determinants of non-compliance of public procurement regulations in Kenyan secondary schools. International Journal of Educational Administration and Policy Studies, 5(7), pp. 154-159, 2013.

[15] Ojo, E. and A. Gbadebo, An assessment of non-compliance with procurement proceedings in procurement of works in Nigeria. International Journal of Economic and Business Management, 2(3), pp. 25-34, 2014.

[16] Azhar, N., R.U. Farooqui and S.M. Ahmed. Cost overrun factors in construction industry of Pakistan. in First International Conference on Construction in Developing Countries (ICCIDC-I), Advancing and Integrating Construction Education, Research \& Practice. 2008.

[17] Bima, A.M., A. Tafida and D.L. Baba, Appraisal of Construction Project Procurement Policies in Nigeria. American Journal of Engineering Research, 4(3), pp. 19-24, 2015.

[18] Memon, A.H. et al., Factors affecting construction cost performance in project management projects: Case of MARA large projects. International Journal of Civil Engineering and Built Environment, 1(1), 2014.

[19] Shwarka, S. and N. Anigbogu. Impact of the Public Procurement Reform on public building projects delivery in Nigeria. in Proc. 28th Annual ARCOM Conference, 2012. Edinburgh, UK: Association of Researchers in Construction Management.

[20] Edquist, C., Public Procurement for Innovation (PPI) - a Pilot Study. 2009, Lund: CIRCLE, Lund University.

[21] Hommen, L. and M. Rolfstam, Public procurement and innovation: towards a taxonomy. Journal of Public Procurement, 9(1), p. 17, 2009.

[22] Rolfstam, M., Public procurement as an innovation policy tool: the role of institutions. Science and Public Policy, 36(5), pp. 349-360, 2009.

[23] Sekaran, U., Research methods for business: A skill building approach. John Wiley \& Sons, 2006.

[24] Giudici, P., Applied Data Mining: Statistical Methods for Business and Industry. John Wiley \& Sons, 2005.

[25] Hayes, A.F., Introduction to mediation, moderation, and conditional process analysis: A regression-based approach. Guilford Press, 2013.

[26] Preacher, K.J. and A.F. Hayes, SPSS and SAS procedures for estimating indirect effects in simple mediation models. Behavior research methods, instruments \& computers, 36(4), pp. 717-731, 2004.

[27] Hayes, A.F., Model Templates for PROCESS for SPSS and SAS in White paper 2013: The Guilford Press. 
[28] Baron, R.M. and D.A. Kenny, The moderator-mediator variable distinction in social psychological research: Conceptual, strategic, and statistical considerations. Journal of personality and social psychology, 51(6), p. 1173, 1986.

[29] Hayes, A.F., PROCESS: A versatile computational tool for observed variable mediation, moderation, and conditional process modeling [White paper]. URL: http://imaging.mrc-cbu.cam.ac.uk/statswiki/FAQ/SobelTest, 2012.

[30] Hayes, A.F. and K.J. Preacher, Statistical mediation analysis with a multicategorical independent variable. British Journal of Mathematical and Statistical Psychology, 67(3), pp. 451-470, 2014.

[31] MacKinnon, D.P., C.M. Lockwood and J. Williams, Confidence limits for the indirect effect: Distribution of the product and resampling methods. Multivariate behavioral research, 39(1), pp. 99-128, 2004.

[32] Hayes, A.F., Model Templates for PROCESS for SPSS and SAS [White paper]. Retrieved on March, 7, p. 2014, 2013.

[33] Uyarra, E. and K. Flanagan, Understanding the innovation impacts of public procurement. European Planning Studies, 18(1), pp. 123-143, 2010.

[34] Preacher, K. J. and K. Kelley. Effect Size Measures for Mediation Models: Quantitative Strategies for Communicating Indirect Effects. Psychological Methods, Vol. 16, No. 2, 93-115, 2011. 